\title{
Relationship of paired-associate learning and single trial free recall ${ }^{1}$
}

\author{
DAVID S. GORFEIN, CHRISTOPHER \\ $A R B A K$, and DIANA GRAVES, New \\ College, Sarasota, Fla. 33578
}

In an effort to understand the relationships among rote verbal-learning tasks, the correlation between components of single-trial free recall and paired-associate (PA) learning were examined. Correlations among three PA lists were high and followed a pattern commonly found in practice effects in motor skills. All PA scores correlated significantly with the learning of the primacy portion of free recall. Most significant is an indication that an analysis of free recall in terms of the serial-position curve is both fruitful and necessary.

A recent symposium (Melton, 1964) was devoted to a call for a taxonomy of human learning tasks. In that volume, Underwood (1964) emphasized the importance of examining the relationships between rote verbal-learning tasks in the development of a theory of memory. Despite these calls for action, comparatively little has been done in the examination of the relationships between tasks. Whimbey and his colleagues (Ryan \& Whimbey, 1968; Whimbey \& Leibhum, 1967) have begun extensive investigations of the digit-span task in its relationship to other situations. In the area of concem of the current paper, Marcia Earhard (1967) and Earhard \& Endicott (1969) have used a measure derived from the free-recall situation (subjective organization) in examining individual differences in serial free recall, serial learning, and paired-associate learning. They found that high scores in subjective organization show better serial recall as well as better paired-associate learning than do low scores in subjective organization. In several studies, the present authors(Gorfein \& Bennett, 1967; Gorfe in, Bennett, Arbak, \& Graves, in press) have found significant correlations between performance in the free-recall task and performance in short-term memory in a Peterson paradigm.

In the present investigation, an analysis was made between performance in the single-trial free-recall situation and performance in paired-associate learning in an attempt to further explicate the relationships between rote verbal-learning tasks.

\section{METHOD \\ Subjects}

Thirty-six New College students were paid to serve as Ss.

\section{Free Recall}

Twenty-four lists of 24 words were randomly drawn from $A$ and $\mathbf{A A}$ words in the Thorndike-Lorge (1964) list. Words were assigned to lists randomly, with the restriction that there were no obvious intralist associations and that no two words occurring consecutively in a list began with the same letter.

All 24 lists were presented in a single session. Items were displayed visually with a Kodak Carousel projector at a 1 -sec rate. Ss were given standard free-recall instructions and were allowed $3 \mathrm{~min}$ for written free recall after each list.

\section{Paired Associates (PA)}

All Ss participated in a two-session PA experiment. Three lists of paired associates were used for this purpose. Each list consisted of the numbers 1 to 15 as stimuli and a different set of medium $\mathrm{m}^{\prime} \mathrm{CVCs}$ (Noble, 1961) as responses. Four random orders of each list were used. Ss were given standard paired-associate instructions and required to learn each list to a criterion of one perfect trial at a $2: 2$ rate. To investigate the possibility that there might be a relationship between retroactive and proactive inhibition as it occurs in the paired-associate learning task and performance in the free-recall situation, we included the following procedure: As a measure of RI, each S learned the first list to criterion, the second list to criterion, and then relearned the first list. Thus, we have an A-B , A-C paradigm and are able to measure retroactive inhibition in terms of both performance on the first relearning trial and in terms of savings from initial learning to relearning. Following the relearning of the first list to criterion, each $S$ learned List 3 to criterion. In a second session (on the average about $24 \mathrm{~h}$ after the learning of List 3), we had each $\mathrm{S}$ releam List 3 . We could then use, as a measure of proactive effects, the first trial of relearning performance and the savings measure.

\section{RESULTS AND DISCUSSION}

For each $S$, a serial-position curve of his recall over the 24 trials was constructed. From these curves, the following scores were derived for each $S$ :
Primacy. Total number of correct recalls that came from five serial positions.

Middle. Total of correct recalls by $\mathrm{S}$ from Serial Positions 6-16.

Slope $P$. The slope of the best-fitting line of the primacy portion (first five positions), treating Point 5 as the low end.

P(STS). An attempt as a measure of that part of the recency portion resulting from $S$ retrieving the contents of his buffer store. $P(S T S)=[P($ Rec e n c $)$ $P(M i d d l e)] /[1-P(M i d d l e)]$, where $P$ refers to the average probability of recall from the specified portion of the curve by a given $S$. It is based on the assumption that recall in the recency portion (Serial Positions 19-24) represents a combination of items stored in long-term memory, those in the buffer store, and those in both. It assumes that items recalled in the middle are an estimate of the probability of retrieval from long-term store.

Total recall. The number of items correctly recalled by a $S$ over the entire 24 lists. Table 1 reports the correlations between the paired-associate learning tasks and the scores derived from free-recall performance. The patterns of correlations between paired-associate learning scores and performance in different portions of the serial-position curve are quite interesting. Most notable is the fact that the learning of all three paired-associate lists correlates significantly with the primacy portion of the serial-position curve, while only the learning of List 1 correlates significantly with the middle portion. The decrease in correlation between the free-recall measures and PA learning as a function of the amount of PA experience a $S$ has had is inexplicable to the present investigators. Before any conclusions about this pattern are drawn, the experiment should be replicated.

The correlations among paired-associate scores are not at all uncommon. It is a common finding in motor-skill tasks that correlations within a particular kind of task increases with experience. It has been suggested that this indicates that the factors influencing performance become less variable in the practiced S (cf. Deese \& Hulse, 1967). A similar pattern of correlations has been reported for the between-trial correlations in multiple-trial free recall (Gorfein \& Bennett, 1967). More detailed investigation is needed to help determine the nature of these factors. In particular, it would be necessary to compare

Table 1

Relationship of Paired-Associate Leaming Scores and Free-Recall ${ }^{3}$

\begin{tabular}{lcccccr}
\hline & PA List 2 & PA List 3 & Primacy & Middle & P(STS) & Total \\
\hline PA List 1 & .70 & .58 & .46 & .35 & .29 & .48 \\
PA List 2 & - & .81 & .49 & .21 & .16 & .36 \\
PA List 3 & & - & .40 & .09 & .04 & .19 \\
\hline
\end{tabular}


paired-associate performance across a variety of materials to see if there were genuine individual differences in paired-associate learning comparable to those observed in free recall (cf. Gorfein, Blair, \& Rowland, 1968; Gorfein \& Blair, in press).

Since the four measures of interference correlate insignificantly with each other, we have used all four measures in attempts to see their relationship to the serial-position curve of free recall. Correlations involving the two measures of retroactive inhibition, the savings on the relearning of List 1 and the first trial of releaming List 1 and the four free-recall measures, are all statistically insignificant, having an absolute value ranging between .02 and .31 . Those involving the two proactive-inhibition measures based on List 3 relearning performance are statistically insignificant, with a single exception: a negative correlation of -.39 between savings on 3 and primacy. An explanation of this unexpected finding is suggested by examining the relationship of the learning of List 3 to the performance in free recall, as well as the relationship of the learning of List 3 and the savings on relearning. As shown in Table 1, primacy in a learning of a third paired-associate list correlate .40 . The obtained correlation between the savings score in List 3 and the learning of List 3 is -.66 If we, therefore, partial out the ability to learn from the correlations between the savings measure and primacy, we find a partial correlation of -18 , which is statistically insignificant. It is our belief, therefore, that the observed negative correlation between the savings score and primacy is due to the large ability-to-learn component reflected in the savings measure.

In general, we have demonstrated a relationship between paired-associate performance and performance in free recall. Most significant is the indication that an analysis of the free-recall situation, in terms of the serial-position curve, yields a set of relationships that could have been glossed over if such a gross measure as total free recall had been employed.

\section{REFERENCES}

DEESE, J. E., \& HULSE, S. H. The psychology of leaming. (3rd ed.) New York: McGraw-Hill, 1967.

EARHARD, M. Subjective organization and list organization as determinants of free recall and serial recall memorization. Joumal of Verbal Learning \& Verbal Behavior, 1967, 6, 501-507.

EARHARD, M., \& ENDICOTT, O. Why are there individual differences in subjective organization during frec-recall memorization? Journal of Verbal Learning \& Verbal Behavior, 1969, 8, 316-319.

GORFEIN, D. S., \& BENNETT, R. W. Analy sis of free-recall over multiple trials. Paper presented at the annual meeting of the Psychonomic Society, 1967.

GORFEIN, D. S., BENNETT, R. W., ARBAK, C.,
\& GRAVES, D. Individual differences in the serial position curve of free-recall. Journal of Verbal Leaming 4 Verbal Behwior, in press.

GORFEIN, D. S, \& BLAIR, C. Fsctors affecting multiple-trial free-recall. Joumal of Educational Psychology, in press.

GORFEIN, D. S., BLAIR, C., \& ROWLAND, C. The generality of free-recall: II. Performance as a function of type of materinl Psychonomic Science, 1968, 13, 111-112.

MELTON, A. W. (Ed.), Categories of human learning. New York: A cademic Press, 1964.

NOBLE, C. E. Measurement of associntion value (a), rated associations (an) and scaled meaningfubess $\left(\mathrm{m}^{\prime}\right)$ for the $2100 \mathrm{CVC}$ combinations of the English alphabet. Psychological Reports, 1961, 8, 487-521.

RYAN, S. D., \& WHMBEY, A. E.STM abilities in LTM tasks. Psychonomic Science, 1968, 10, 297-298.

THORNDIKE, E. L., \& LORGE, I. The teacher's word book of 30,000 words. New York: Bureau of Publications, Teachers College, Cohumbia Untversity, 1944.

UNDERWOOD, B. J. The representativeness of rote verbsl learning. In A. W. Melton (Ed.), Categories of human leaming. New York: Academic Press, 1964.

WHIMBEY, A. E, \& LEIBLUM, S. L. Individual differences in memory span with and without activity intervening between presentation and recall. Journal of Educational Psychology, $1967,5,311-314$.

\section{NOTES}

1. The research reported was done under the supervision of the senior athor and fulfills an independent study requirement of the two junior authors.

2. Written at the Human Performance Center, University of Michigan. We gratefully acknowledge the support of Dr. Arthur W. Melton in the preparation of this report.

3. For $\mathrm{p}>.325, \mathrm{p}<.05$; for $\mathrm{r}>.418, \mathrm{p}<.01$.

\section{The intuitive estimation of means with auditory}

presentation

\author{
G. LOWE, University of Hull, Hull, \\ England
}

Subjects were required to make intuitive estimates of the means of samples of 10 or 20 numbers with auditony presentation. As in previous experiments, performance was fairly accurate, and increased sample size and variance resulted in overestimation. Accuracy was also affected by the value of actual means and there were significant interactions between sample size and variance and between sample size and actual mean. The observed tendency for intuitive estimates to be more accurate with auditory than with visual presentation was thought to be a feature of sequential processing strategies.

A previous investigation (Bulger, Hiles, \& Lowe, 1969), along with earlier studies, found that Ss' performance as intuitive descriptive statisticians was quite accurate, although error scores increased with sample size and information-processing rate. It was suggested that the increased sample size might necessitate the use of different strategies (possibly in the form of sequential, as opposed to simultaneous, processing). Most studies of the intuitive estimation of means have, in fact, used visual presentation of the data (number samples or anays), which permits the use of either sequential (successive scanning) or simultaneous (parallel) processing strategies, or, indeed, some mixture of the two. Auditory presentation is, of course, restricted to sequential inputs, and, in this case, Ss will presumably adopt a sequential strategy of information processing to arrive at an estimate of the mean of a sample of numbers. The aim of the present investigation was to determine the accuracy and the characteristics of $\mathrm{Ss}^{3}$ estimation performance under such conditions.

\section{APPARATUS}

Numbers (integers) ranging between 0 and 20 in random order were recorded on magnetic tape for presentation by tape recorder. Lists (or samples) consisted of either 10 or 20 numbers, and distributions were symmetrical. There were 14 different combinations of means and variances for each sample size. The 7 sample means were $4,5,6,7,8,9$, and 10 , each with constant variance equal to 6.4 ; the 7 sample variances were $6,11,18,27,36,51$, and 66 , each with constant mean equal to 10 . There were, thus, 28 different types of number samples. Each of these was presented in four different random arrangements, making 112 different presentations altogether.

\section{PROCEDURE}

The Ss were told that they would be presented with lists or samples of numbers, and that they had to estimate the mean of each sample. They were given a preliminary practice session of 20 presentations, none of which were included in the main 